Canadian Journal of Higher Education Revue canadienne d'enseignement supérieur

Volume 48, No. 1, 2018, pages 82 - 98

\title{
Action Research for Graduate Program Improvements: A Response to Curriculum Mapping and Review
}

\author{
Michele Jacobsen \\ Sarah Elain Eaton \\ Barb Brown \\ Marlon Simmons \\ Mairi McDermott \\ University of Calgary
}

\begin{abstract}
There is a global trend toward improving programs and student experiences in higher education through curriculum review and mapping of degree programs. This paper describes an action research approach to program improvement for a course-based MEd degree. The driver for continual program improvement came from actions and recommendations that arose from an institutionally mandated, year-long, faculty led curriculum review of professional graduate programs in education. Study findings reveal instructors' perceptions about how they enacted the recommendations for program improvement, including (1) developing a visual conceptualization of the program; (2) improved connections between the courses; (3) articulation of coherence in goals and expectations for students and instructors; (4) an increased focus on action research; (5) increased ethics support and scaffolding for students; and (6) the fostering of communities of practice. Study findings highlight strengths of the current program and course designs, action items, and research needed for continual program improvement.
\end{abstract}




\section{Résumé}

Il existe une tendance mondiale à améliorer les programmes d'études supérieures ainsi que l'expérience des étudiants par la révision et l'articulation des programmes. Nous décrivons une approche rechercheaction pour améliorer un programme de cours de maîtrise en éducation. Une révision des programmes d'éducation au niveau supérieur imposée par l'institution et menée par des membres de la faculté a engendré des actions et recommandations vers l'amélioration des programmes. Les résultats montrent les perceptions des chargés de cours en ce qui concerne la manière dont ils ont réalisé ces recommandations. Parmi celles-ci, (1) développer une conceptualisation visuelle du programme; (2) améliorer les connexions entre les cours; (3) clarifier les buts et les attentes des étudiants et professeurs; (4) élargir le focus sur la recherche-action; (5) offrir aux étudiants l'échafaudage et plus de soutien pour l'éthique; et (6) encourager des communautés de pratique. Les résultats de l'étude soulignent les forces du programme actuel et des configurations de cours, et des suggestions pour action et recherche qui seraient nécessaires pour continuer à améliorer le programme.

\section{Introduction}

Universities are recognized as centres for research and knowledge mobilization, innovation, and discovery. In the past two decades, we have seen an increased focus on the quality of student experience and the quality of teaching. Research from Canada, the United States, the United Kingdom, and Australia points to an increased emphasis on quality teaching and learning, and a trend toward curriculum review, reform, and quality assurance initiatives in higher education focused on the student experience (Dyjur \& Lock, 2016; McNay, 2009; Oliver, Ferns, Whelan, \& Lilly, 2010; Oliver \& Hyun, 2011; Spencer, Riddle, \& Knewstubb, 2012; Uchiyama \& Radin, 2009; Wooltorton et al., 2015). Common challenges addressed through curriculum review and program renewal in graduate education include low student satisfaction, attrition rates, time to completion, fragmentation of programs and courses, narrowly defined specializations, disconnection from professional practice, and inaccessible and inflexible timetables for students who work full time (Willis, Inman, \& Valente, 2010). In this paper, the authors describe the broader context of curriculum review that informed the Werklund School of Education (WSE), University of Calgary's (2015b) curriculum review process, and provide details about a specific series of cohort-based research courses in a Master of Education program that is the focus for this action research. The authors describe how the iterative process of action research on our own practices unfolded and informed the core findings from the research. The paper concludes with the difficulties and limitations of an action research approach to enacting change post-curriculum review as we point to further research and reflections that leave the research necessarily in medias res.

\section{Global Context of University Curriculum Review Processes}

Oliver et al. (2010) describe how a university-wide curriculum renewal and mapping initiative at Curtin University, Australia, focused on measuring the quality of higher education, 
with a specific focus on graduate attributes. The curriculum mapping and comprehensive course review process served to improve the quality of teaching and led to significant improvements in student satisfaction. Changes to programs at Curtin University included improved staff engagement and student learning. The mapping process moved course design beyond individualistic instructor perspectives to a more student-centred view of learning.

McNay (2009) posits that curriculum mapping-generating a graphical portrayal of the relationships between course and program goals and expected student outcomes-is an essential process for curriculum review. Uchiyama and Radin (2009) found that curriculum mapping at an American college of education allowed for curricular changes that, in turn, enhanced student engagement and collaboration among faculty in teacher education. Curriculum review and mapping, thus, have been demonstrated as effective design strategies for the enhancement of curriculum redesign and student engagement (McNay, 2009; Oliver \& Hyun, 2011; Spencer et al., 2012). In findings from a qualitative study of a university-wide curriculum review process and mapping framework for data collection, Dyjur and Lock (2016) emphasize that such reviews must focus on enhancing the student learning experience and addressing quality assurance. They identify key data sources for curriculum review, such as student data, surveys, interviews, focus groups, stakeholder feedback, and curriculum mapping. Three strategies are described for engaging curriculum mapping online: (1) templates using standard tools, (2) online survey tools, and (3) specialized curriculum mapping software. Importantly, Dyjur and Lock (2016) argue that curriculum review must be evidence-based, and a process that delineates both the strengths of a program, as well as the quality of the student learning experiences. Curriculum mapping carried out at La Trobe University in Australia (Spencer et al., 2012) provided a starting point for faculty to engage in ongoing curriculum development; action items and recommendations provided an agenda for curriculum changes carried out over three years within the faculties of law and management. Similarly, the WSE's review of professional graduate programs yielded curriculum, administrative, education development, and programmatic action items and recommendations to guide continuous improvement and design over five years.

The University of Calgary's “Academic Quality Assurance Handbook: Curriculum Reviews" (2015a) is used as a "framework for quality improvement through a focus on setting goals, measuring performance, and periodically re-evaluating the core mission at multiple levels of the University academic enterprise" (p. 2). The institutional purpose for a campus-wide curriculum review process was to document the quality of curriculum through an "academic staff-led critical examination of each undergraduate and coursebased master's program for the purpose of optimizing the learning outcomes of that program...[and to] generate an action plan for improving the program" (p. 2). Key emphases in this quality assurance process were (1) collaborative curriculum review and mapping processes focused on continual improvements in program quality, and (2) enhancement of the student experience.

\section{Context of the Study}

During the 2014-15 instructional year, the WSE enacted a year-long, faculty-led curriculum review and mapping process for all course-based professional graduate programs. The WSE offers professional graduate programs in both educational research and educa- 
tional psychology that provide students with the opportunity, and multiple pathways, to earn a Doctor of Education (dissertation-based), a course-based Master of Education or Master of Counselling degree. Programs are offered in eight specialized areas of study: (1) curriculum and learning, (2) adult learning, (3) leadership, (4) learning sciences, (5) language and literacy, (6) school and applied child psychology, (7) counselling psychology, and (8) interdisciplinary studies. Professional graduate programs have been intentionally designed as cohort-based learning experiences for students that emphasize practitioner led, field-based research to inform changes and innovations in professional practice in education and in psychology.

The curriculum review and mapping process built upon established approaches to action research, collaborative design, reflective practice, and teaching in the faculty (Brown, Eaton, Jacobsen, Roy, \& Friesen, 2013; Brown, Dressler, Eaton, \& Jacobsen, 2015), that were cultivated through a major program redesign and faculty reorganization in 2010-11. Along with other education faculties in Canada, WSE has been engaged in the ongoing redesign of graduate programs to reflect the practical wisdom, signature structures, and signature pedagogies of the discipline (Shulman, 2005, 2007) in order to best engage students in meaningful scholarship that advances knowledge in professional practice (Willis et al., 2010). The curriculum review (CR) process was undertaken as a formative component of the overall quality strategy for four master's degree programs (i.e., Master of Counselling, Master of Education School and Applied Child Psychology, Master of Education Specialist, and Master of Education Interdisciplinary). The courses and program sequences in each of these programs have been designed to provide a demanding, coherent, and high-level academic experience to educate students as leaders of professional practice. The CR focused on continued development of curriculum in 22 topical study areas to enhance student experience across specializations. Through the CR process, faculty gathered multiple forms of data to examine individual courses, as well as the integration of the courses to form comprehensive programs of study in each of the degrees. A curriculum mapping process gauged the extent to which individual courses aligned to national graduate competencies (Council of Ministers of Education Canada, 2007) and to local program goals. From the data analysis, recommendations and an action plan were developed to guide ongoing improvements in the four master's programs (University of Calgary, 2015b).

The university-mandated CR process identified strengths of the current graduate programs and course designs, as well as gaps. This action research study focused on educational development and program improvements for the Master of Education Interdisciplinary (MEd Interdisciplinary) degree pathway, with a specific focus on the action items that resulted from the curriculum review and mapping process for the four research courses. The MEd Interdisciplinary is a course-based degree route that provides students with a critical awareness of current problems or new insights, at the forefront of academic disciplines, fields of study, or areas of professional practice. Students complete 12 courses over three steps: Step 1: Students complete four, three-credit courses in a specialized topic and earn a Graduate Certificate; Step 2: Students complete four, three-credit courses in a different topic and earn a second credential, a Graduate Diploma; Step 3: In the third step, called the Research Step, students complete four, three-credit courses in educational research that have been designed to ensure learners develop research depth through a focus on learning about research, doing research, and writing research (see Figures 1 and 2). 


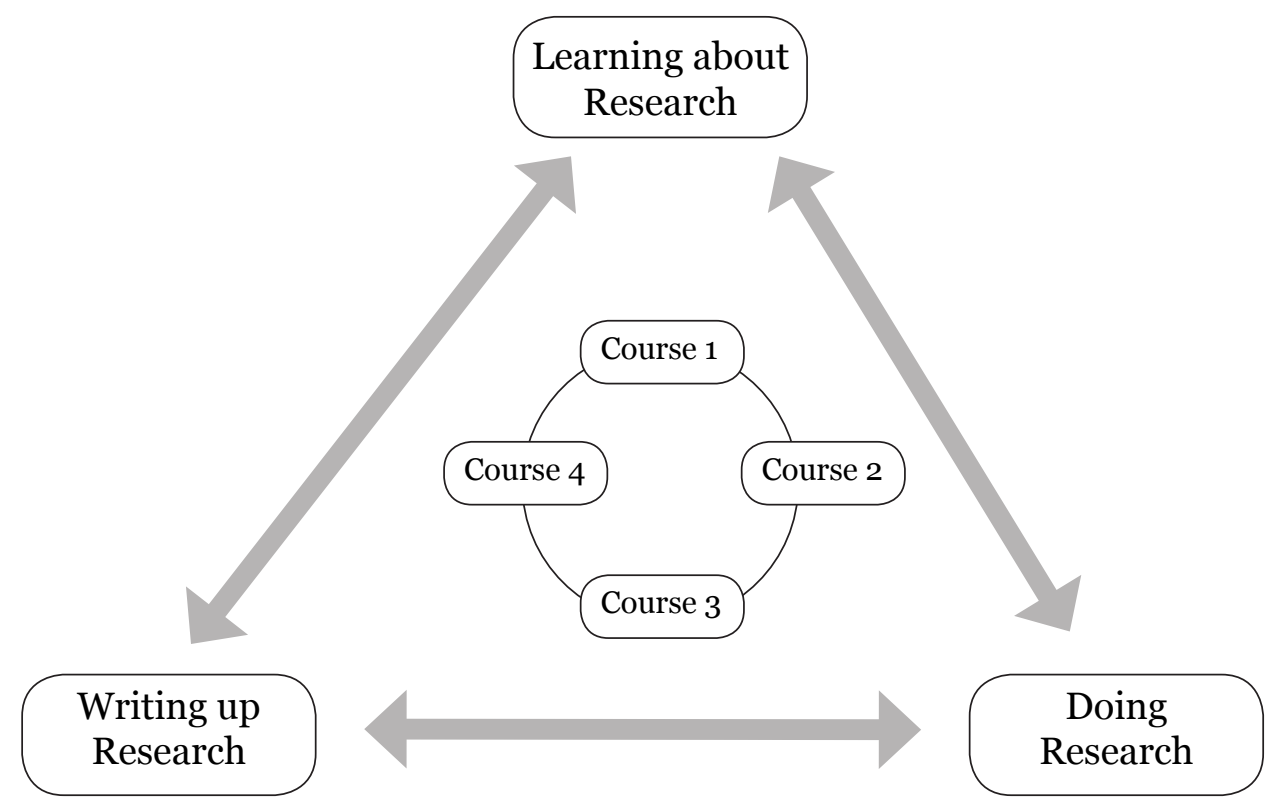

Figure 1. A Descriptive Model Showing How the WSE Teaches Educational Research across Four Required Research Courses

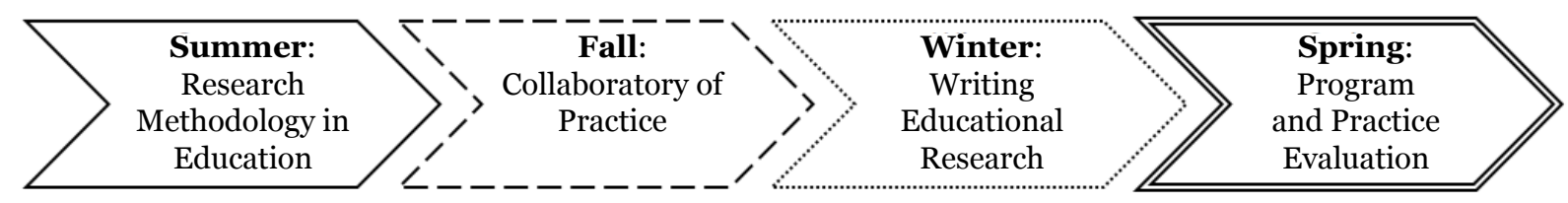

Figure 2. Four Course Sequence of the Required Research Courses in the Master of Education Interdisciplinary Program

The present action research was carried out by the academic coordinator of the Research Step, who is also the associate dean, in collaboration with several instructional team members. In our overlapping roles as academic coordinator, instructors, and coresearchers, we engaged in a collaborative practice of collegial review and revision of the four educational research courses to ensure a coherent program sequence and experience for students in response to the action items and recommendations from the CR. Similar to Uchiyama and Radin's (2009) findings from curriculum review, a welcome benefit of the curriculum mapping and review process-and subsequent work planning, implementing, and studying several changes-was strong collegiality and collaboration in our research team. Our individual instructional approaches and reflections on course-based teaching and administrative experiences were shared through face-to-face and online teaching/ research team meetings. Regular meetings allowed us to discuss and debate how national standards for graduate education (Council of Ministers of Education, 2007), educational research methodologies and methods, and instructional practices should be reflected in 
each of the four research courses in the final Research Step of the MEd Interdisciplinary degree. Instructors who were involved in the original curriculum review contributed insights to the action plan based on their experiences teaching multiple sections of the research courses, and also their reflections on practice and program coherence.

\section{Methodology}

Building upon an established approach to collaborative instructional teaching and design teams in the WSE, throughout the CR process, program changes to the Research Step were enacted in a fluid and non-linear process. Indeed, changes are still ongoing as this research team continues to reflect, collaborate, and study the changes from our perspectives as instructors and academic coordinator. In research on the inclusion of sustainability as a central curriculum principle at one university, Wooltorton et al. (2015) found that action research could be applied to curriculum development to provide visions and mediations for organizational change. Likewise, in the present study, the research team engaged in a process of action research with a goal of simultaneously acknowledging and disentangling some of the complexities of programmatic change in higher education. A key ethical principle of action research is to ensure that "all relevant persons, committees, and authorities have been consulted, and that the principles guiding the work are accepted prior to commencing the research" (MacDonald, 2012, p. 45). This principle was achieved through the curriculum review process - which included input from administrative, instructional, student, and staff stakeholders-as well as within the study presented here, which includes administrative and instructional team members who collaboratively teach and support students in the Master of Education program, and who are also engaged in an ongoing program of action research together (Brown, Eaton, Jacobsen, Roy, \&Eaton, 2013; Brown, Eaton, Dressler, \& Jacobsen, 2015).

The framework for action research informing our study includes (1) planning; (2) observing and acting; (3) systems thinking, enacted through critical reflection; and (4) engaging in continuous iterations of this process (Kemmis, McTaggart, \& Nixon, 2014; MacDonald, 2012; McNiff, 2013, 2014; Parsons, Hewson, Adrian, \& Day, 2013; Wooltorton et al., 2015). The researchers enacted and report on an iterative process of action research that occurred over a 12-month period. The process included both formal and informal team meetings to engage in a process of group reflection, as well as individual reflection, action, and documentation.

\section{Data}

In the following section, we describe each of the data sources informing this action research, from regular team meetings, teaching journals, communications, administrative documentation, and narrative reflections.

Team Meetings. Notes, emails, and minutes were maintained from collaborative team meetings each term. To optimize the teaching and research team's time, and limit the need to travel, the three or four meetings per term were conducted in person, online, or mixed with some participants attending in person and others joining via digital conference methods.

Teaching Journals. Each researcher-instructor maintained a teaching journal with analytic memos (Miles, Huberman, \& Saldaña, 2014) that captured key moments about 
student successes, challenges, and common questions about the learning tasks. The journals provide a chronological record of the progression of changes that occurred during the redesign process.

Communications. All communications were maintained between the academic coordinator and instructors. The record of electronic mail flowing among the team members also provided a chronological record of key messages that were communicated and debated among the group.

Administrative Documentation. The academic coordinator gathered all the administrative documentation related to the curriculum review and administrative processes used for managing the program and resources (e.g., processes for developing stackable degrees, arranging class cohorts, supporting instructors, scheduling, tracking progress, communications, and so on).

Narrative Reflections. Each researcher individually developed narratives describing personal experiences with instruction and with program changes that were shared for group analysis. Researchers developed personal narratives by reflecting on their own teaching journals, notes, communications, calendars, and documents. The team meeting notes, communications, and shared administrative documents, such as the curriculum review documentation, also informed personal narratives, excerpts from which are quoted below.

\section{Analysis}

The analysis of the data included (1) coding for themes (Miles, Huberman, \& Saldaña, 2014); (2) researcher cross-checks for trustworthiness and relevance; (3) visual representation of data in matrices; and (4) overlaying of the themes from the data with action items from the original CR action plan.

Coding for Themes. In order to begin data analysis, the research team assembled all sources of data. Once the data were assembled and organized, and the research team agreed that the narrative reflections were complete, two members of the research team coded the data for themes related to the research problem of enacting desired program changes in response to curriculum review. The two researchers reviewed the narrative reflections and individually identified emerging and reoccurring themes.

Researcher Cross-Check. Themes from the initial coding process were crosschecked and discussed by the two members of the research team in order to triangulate similar readings and interpretations of the various forms of data; to establish trustworthiness and relevance of themes in the context of the CR; and to synthesize and collapse the analysis into key themes. Five key themes emerged that were carried forward in the analysis: (1) program understanding, (2) program commitment, (3) student challenges, (4) design team challenges, and (5) community of practice.

Visual Representation of Data in Matrices. Once the five key themes were identified and all the narrative reflections were coded, the data were reassembled in two phases. In the first phase, matrices were created that listed the themes and excerpts from the narrative reflections.

Overlaying of Themes from Data with Curriculum Review Action Plan. The second phase of reassembling the data involved examining themes emerging from the narrative reflections in relation to the action items from the original CR action plan. This 
approach to synthesis allowed for a further refining of core themes and the identification of an emerging theme or area for improvement that was not previously amplified in the original CR action plan. Table 1 illustrates the results of the second phase of data reassembly that resulted in an alignment of key themes to the CR action plan.

Table 1.

Alignment of Analytical Themes to Curriculum Review Action Plan

\begin{tabular}{|c|c|c|}
\hline Analytical Themes & Description & $\begin{array}{l}\text { Needs Emerging from } \\
\text { Curriculum Review Action Plan }\end{array}$ \\
\hline Program Understanding & $\begin{array}{l}\text { Fostering a better understand- } \\
\text { ing of the broader program }\end{array}$ & $\begin{array}{l}\text { Program conceptualization } \\
\text { needed }\end{array}$ \\
\hline Program Commitment & $\begin{array}{l}\text { Evidence of commitment to im- } \\
\text { proved continuity and cohesive- } \\
\text { ness in the program }\end{array}$ & $\begin{array}{l}\text { Course connections needed } \\
\text { Coherence in goals and expecta- } \\
\text { tions needed }\end{array}$ \\
\hline Student Challenges & $\begin{array}{l}\text { Identifying key student } \\
\text { challenges in the program }\end{array}$ & $\begin{array}{l}\text { Ethics support and scaffolding } \\
\text { needed }\end{array}$ \\
\hline Design Team Challenges & $\begin{array}{l}\text { Identifying challenges in design- } \\
\text { ing research-oriented learning } \\
\text { experiences }\end{array}$ & $\begin{array}{l}\text { Greater methodological focus on } \\
\text { action research needed }\end{array}$ \\
\hline Community of Practice & $\begin{array}{l}\text { Focus toward improved teach- } \\
\text { ing in a community of practice } \\
\text { (e.g., presence, signature peda- } \\
\text { gogies, formative assessment } \\
\text { strategies, etc.) }\end{array}$ & \\
\hline
\end{tabular}

\section{Analytical Themes and Program Improvements}

As depicted in Table 1, through the CR and mapping of the overall program discussed in previous sections, the five analytical themes informed and were informed by the following six program improvements: (1) visual conceptualization of the program, (2) improved connections between the courses, (3) development of coherence in goals and expectations, (4) increased focused on action research, (5) increased ethics support and scaffolding, and (6) fostering communities of practice. In this section, while we disaggregate the themes across the program improvements, it ought to be noted that each of the six program improvements overlaps with, and informs, the other key areas.

1. Visual Conceptualization for Program. In alignment with an action item from the curriculum review about program coherence, the research team found that one of the most pronounced themes that emerged from the data was the experience and felt importance of the instructors developing a clear image of how the four research courses in the Research Step were interconnected and built upon each other (see Figure 1), and to communicate these connections with students. One instructor reflected, "I confidently discussed the course outline, answered the questions the students had and briefly out- 
lined the series of courses they would be taking." This reflection from a newer instructor on the team suggests that the team's collaboration was invaluable for instructors to develop confidence and ability in communicating to students the planned trajectory of the research process through the coursework sequence. Figure 1 graphically depicts the research team's visualization of the four courses and how these interconnect. Coming to a visualization that represented each of our understandings regarding the interconnections and flow took many debates and conversations.

2. Course Connections. Building upon the clear visualization developed for the courses, the research team reworked the course outlines to improve communication about the connections between them, and also refined each course further as each was taught. One team member reflected, "With intention we chart out the unfolding of the courses and how they link together early on in the [first] course." In the planning and reorganizing of the course outlines, the team ensured that each course prepared for and built into the next course. In the course outline revision process, the team continually considered the course goals and design in relation to the interconnectivity throughout the program. For example, in the narratives, instructors reflected on how the team intentionally incorporated ethics conversations into the first course in preparation for the second course when students would possibly design research that required ethics approvals. The team was able to amplify the interconnections between courses by working simultaneously on one course outline while always looking ahead to what would be needed in the next course. This iterative design work required ongoing communication among the research/teaching team and frequent check-ins to dialogue through the process and ground each other and instructional decisions in the broader context of the flow of courses. More experienced team members helped to frame the upcoming courses during collaborative teamwork and team meetings.

3. Coherence in Goals and Expectations. It was noted in the narratives that an understanding of program coherence developed over time and with experience teaching in the program. There was value in repeat experiences for instructors and opportunities to teach during different stages of the program. One narrative, for example, noted, "Looking back at the research courses I taught helped me to get a sense about how these courses have become situated within the graduate program." The research team found that communicating the coherence in goals and expectations is particularly important for new instructors in the program. In this cohort-based program, the academic coordinator took on the role of team leader in the research and redesign of the MEd program. The role of the team leader in instilling a sense of coherence within the team of instructors was critical in developing coherence in goals and expectations for students. The team leader's experience with the collaborative process and support in providing a space for this structure for instructors was appreciated in particular by a newer member of the team:

I am grateful that [team leader] organized this meeting and I will have the chance to connect with the other members of the...instructional team. I know, from previous discussions with team members that the course underwent some changes, yet I didn't realize the extent of the changes made, nor how pivotal previous cohorts' feedback was in the changes that were made this year. 
Another instructor commented on the way the meetings and collaborative work were designed: "All members of the redesign team have the opportunity to offer input and share their ideas. The de facto manner these teams operate is through participatory decision making." The instructors reflected on multiple communication methods (virtual meetings, email exchanges, shared documents and resources, face-to-face chats) used to share and elaborate upon program goals and expectations for the research courses both among the instructional team and as that seeped into the courses we were teaching: "With sharing this feedback in our scheduled team meetings we realized that this was also a shared moment of discussion with other sections, instructors and students."

Communicating program coherence with students was also noted as important during data analysis. For example, instructors discussed how live online synchronous sessions were used to share expectations for student research and inquiry and to address any student misunderstandings. Another instructor discussed how making provisions for multiple modes of communication or entry points was important in developing a sense of shared expectations, communicating program coherence, and responding to student inquiries: "Many students [reached out to me] via phone call, virtual meet-ups, be it Facetime, Skype, Adobe Connect, face-to-face, or Virtual Office..." Conversations with students were situated within a grand, shared conceptual framework of the program as a coherent graduate education and research experience.

The research team found that there are benefits to having continuity of instructors within the cohort-based program for communicating program coherence and building relationships with the students (e.g., one instructor for two or three of the research courses):

From an instructor perspective, I felt as though I took on a supervisory role for a non-supervisory program.... I got to know the students in a way that allowed for personalized learning. By [the third or fourth course], I had a real sense of where a student could go in their writing.

The research team found that program coherence and continuity between courses goes beyond having common course outlines and communicating common program goals. For example, as part of the signature pedagogies in the program, several instructors noted, "Formative assessment seems to be a key part of the positive course experience. We also divide students into smaller groups, called studio groups to manage formative feedback strategies and keep online interactions manageable." Instructors noted that formative assessment practices were explicit in the course outlines, but that each instructor also incorporated their own approaches to providing feedback. As the program continues to evolve, courses will continue to undergo redesign and new members will join the collaborative instructional teams. Findings from this action research suggest that it will be important to continue emphasizing coherence and continuity in the program and to provide supports for instructors to share understandings of signature pedagogies and assessment practices across the student cohorts.

4. Increased Focus on Action Research. During team meetings, a regular item that was discussed for improvement was the need to increase student understanding of action research. One instructor noted, "Based on my experiences in teaching the Collaboratory course, I have regularly received feedback from students including recommendations to increase experiences with action research.” To address this need, the instruction- 
al team revised the Collaboratory course outline to include readings on action research (Hendricks, 2016). However, this minor change seemed insufficient. The team recognized that learning intentions related to action research were needed in the earlier stages of the program. As such, the team revisited all four of the research courses to strengthen the methodological focus on action research in the learner outcomes and criteria for assessment. One instructor reflected, "The redesigned course outline for the first course includes an emphasis on action research to provide scaffolding toward the Collaboratory [course]." From our collective perspective, it seems as though embedding a required textbook, readings, and formal discussions of action research in the first course of the Research Step has supported student learning in a methodological approach that they, as educators and school leaders, are drawn to the most. The research team plans to gather data from students to evaluate how the increased emphasis and enhanced discussion of action research in the four research courses impacts students' understanding and enactment of action research overall.

5. Ethics Applications. A program goal is for graduate practitioners to develop the ability to lead and study change and innovation in education. Related to that goal is providing Master of Education students the opportunity to obtain ethical approval to complete field-based research in schools and classrooms. Students can also carry out independent inquiries without collecting data from human participants as part of their capstone research project. In earlier cohorts, few students elected to apply for individual ethics approval to carry out field-based research; reasons include the time constraints involved in receiving approval from the university research ethics board and from school jurisdictions. One instructor reflected on earlier experience: "In a class of 27 students, I had four students choose the individual ethics approval option." One CR action item was to increase student engagement in field-based research. During instructor team meetings, several strategies and scaffolds were discussed to improve course and instructional supports and to expand the timeline for students who were interested in pursuing field-based research requiring ethics approval. As a result, information about ethics applications was provided earlier in the program, first during orientation prior to the start of coursework, and then during the first research course. Students were supported in preparing ethics applications prior to the second course, the Collaboratory of Practice, to ensure sufficient time for approvals from the university and from school jurisdictions. The academic coordinator worked with instructors to support the field-based research and ethics application process with students particularly toward the end of course one. One instructor commented, "This amplification of the ethics process allowed for more space/time for students to get organized and apply for ethics."

Building upon the development of a more comprehensive picture of the program, instructors were able to better time course-based discussions of the ethics application process, and to provide earlier support for students who wanted to pursue field-based research. Embedding the TCPS 2: CORE tutorial (an ethics requirement for Canadian researchers) into the first course was helpful in preparing students for research ethics earlier in the program. Approximately one-third of the students in the Research Step $(n=$ 32) now apply for ethics approval to conduct field-based research. An ongoing challenge to address is how to provide ongoing support to students in opening and closing ethics applications. Presently, the academic coordinator holds that role; however, as the number 
of students submitting ethics applications continues to increase, then the workload will become unsustainable for one faculty member. Ongoing development of strategies and structural supports for ethics applications, approvals, and documentation is needed.

6. Community of Practice as a Framework. Overall, working with the five key actions from the CR and with data collected for this action research, it is clear that a community of practice emerged both among the students in the courses and among the research/teaching team. Our culminating experience ties our story together; taking an action research approach to enacting items from curriculum review strengthened the program and our community of practice. Our results show, through narrative reflections on our individual and collective practices and other sources of evidence (curriculum review, team meetings, communications, and documents), that we experienced the redesign as one that supported our own deep learning and development, both as action researchers and as educators. For future research, the research team intends to collect data from students to analyze their perspectives and experiences in the program in order to understand the impact of the changes, the role of communities of practice (at both levels; students and instructors), and to further improve the MEd Interdisciplinary program and courses.

\section{Discussion and Continuing the Action Research Cycle}

In this discussion section, we share some of the entanglements that emerge in a process of action research and collaboration among post-secondary teaching and leadership teams. We worked collaboratively to share understandings, refine ideas for clarity, and support one another in understanding how the program unfolded with the changes that were made as a result of the CR. Throughout the action research and teaching process, there were several different ways we worked collaboratively to conceptualize, revise, and support the four required research courses in the MEd Interdisciplinary program (see Figure 2). We describe here three types of collaborative instructional teams that informed program conceptualization, teaching and learning, and continual program improvement: (1) course redesign teams-in these teams, we revised the course outlines together. The purpose of this collaboration was to revisit the articulation of course learning intentions, signature pedagogies, learning tasks, and assessments; (2) common course teams-in these teams, all members were assigned different sections of the same course and taught different cohorts of students during the same term. Meeting regularly throughout the term, common course teams supported each instructor in teaching the course, responding to student issues as they arose, and problem solving together; and (3) course pairing teams-in these teams, all members taught different courses with the same cohort of students during the same term. The purpose of this collaboration was to ensure that different courses were coordinated and offered students a manageable work timeline throughout the term.

In the analysis of narrative reflections, it became evident that there were some challenges that arose as a result of working in collaborative design and teaching teams, such as time, idea negotiation, redesign progression, and balancing course pairings.

\section{Time}

Collaborating with others to revise a course that fits within a prescribed program can be challenging for faculty members given the extra time commitment. An instructor reflection animates a unique challenge for part-time academic staff who choose to work 
collaboratively: "For me, devoting time to redesign and meeting with instructor teams is the most challenging part. As a sessional instructor, the redesign work often occurs prior to the contracted term, so this may seem like voluntary work and can be time consuming during a time when instructors are preparing for their courses...." Despite the time commitment to meet with a collaborative team, the instructors all agreed they gained valuable insights and support from meeting regularly with colleagues to share ideas and resources prior to and during course-based teaching. For instance, new instructors reported benefits from the time saved in finding resources and drawing upon other instructors' pedagogical approaches, as one noted:

Periodically, folks would share resources with the instructional team: key places for students to consider publishing; already published articles from students who have taken this series of courses in the past; and organizational tools. While we all worked from the same course outline, each of us approached our classes differently as far as I could tell.

Collaboratively sharing learning resources and pedagogical strategies was a valued approach for improving instruction and also resulted in deep learning for each instructor.

\section{Idea Negotiation}

Another challenge in team collaboration is idea negotiation. Members of the collaborative design teams have the advantage of spending countless hours discussing and negotiating ideas and understanding the rationale for each redesign decision (Brown, Eaton, Jacobsen, Roy, \&Eaton, 2013; Brown, Eaton, Dressler, \& Jacobsen, 2015). There may not be full agreement when negotiating ideas about the learning intentions, signature pedagogies, learning tasks, and assessments; the diversity and range of stances may result in designing a course that is not fully accepted or enacted the same way by all instructors who teach the course. One instructor noted,

In my experiences, I have contributed to debates about assessment practice in inquiry projects to determine when formative assessment should be used versus summative assessment. I believe we could improve on idea negotiation by tracking the parts of the redesign that were debated. It would be helpful to return to these items as follow-up discussions with the teams.

One recommendation from this research is to find ways to document the redesign process and idea negotiation across semesters to ensure that issues get revisited regularly and discussed with subsequent design teams.

\section{Redesign Progression}

The complexity of collaboration seems to increase as the redesign process continues year after year. For example, each year new instructors are added to the collaborative design teams who lack the prior experience and understanding about each design choice. Thus, it can be a challenge to fully transition new members. Enculturating a new instructor into an existing collaborative team requires time for sharing and discussion, and time to reexamine designs and review the rationale for choices made. The researchers found that re- 
turning to those decisions and reflecting upon them with new instructors helped to ground the team's understanding of decisions and to determine whether the design was still working for the present context and for meeting graduate student needs. Ongoing research with instructors who are new to the collaborative design and teaching process can shed light on their experience of this process. Finally, each instructor interpreted the course redesign process and enacted the course in their unique way. One instructor observed,

As part of the redesign progression, I would argue it is valuable to bring together colleagues (experienced and inexperienced) that are teaching the same courses in order to negotiate ideas and deepen understanding about the learning intentions, learning tasks, and assessment strategies. This will not guarantee the courses will unfold in the same way; however, it will give all instructors the opportunity to engage in the collaborative process of understanding the rationale behind the design decisions.

\section{Balancing Course Pairings}

There can be challenges in collaborating with colleagues who are balancing workloads for two different courses taught during the same term to the same cohort. One instructor reflected on his or her experiences in coordinating course pairings: "This has improved dramatically over the past couple of years. A few years ago I would systematically find out from the students if they were taking two courses simultaneously and if the due dates for assignments occurred on the same day." The CR pointed to the need to foster collaboration among instructors who are teaching two different courses to the same student cohort in a term, and a greater coherence and complementarity between courses has been the result. When instructors are not on an instructional team (due to teaching different courses) this can become even more challenging. Individual instructors may expect to teach her or his course as a stand-alone entity, even within a cohort-based, and coherently designed MEd program. The role of academic coordinator is to actively seek out spaces for all instructors to connect and collaborate, such as was done with the instructional team assembled in this research, so that conversations about program and teaching can regularly occur in an extended community of practice. Thus, knowledge of students' other program obligations (e.g., enrollment in multiple courses simultaneously) has been found to be helpful for instructors in designing and navigating course-based teaching. In addition, another instructor's reflection suggested that "instructors feel restricted by the course design and are unsure about how much flexibility is permitted in making course changes. Making slight changes to the course timeline may not be sufficient to alleviate work overload." This stated challenge suggests that more attention is needed to redesigning course pairings. Despite the challenges, collaborative teamwork within a community of practice was found to be an effective strategy to develop a clear conceptualization of the MEd Interdisciplinary degree and enact program changes. Instructors collaboratively developed a clear conceptualization of how the four research courses fit together with program outcomes from research design, to field based inquiry, to students writing the final research report. In summary, as instructors reflected on the benefits of collaboration to improve program conceptualization and design, they also noted several challenges (e.g., time, idea negotiation, redesign progression, and balancing course pairings). 


\section{Conclusion}

The findings from this action research emerged from enacting and studying program improvements in a Master of Education program and serve to provide direction for ongoing research. The authors note that the six program improvements were key in cultivating a more coherent program for Master of Education students and can inform further study on improving programs and student experiences in higher education. This study adds to current literature on curriculum review and mapping, and highlights the value of an action research approach to collaborative design and enactment of actions for program improvement. Ongoing research is needed on how to support collaborative design and teaching teams to address challenges such as additional time for meetings, idea negotiation, and redesign progression.

\section{References}

Brown, B., Eaton, S. E., Jacobsen, M., Roy, S., \& Friesen, S. (2013). Instructional design collaboration: A professional learning and growth experience. MERLOT Journal of Online Learning and Teaching, 9(3). Retrieved from http://jolt.merlot.org/vol9no3/ brown_0913.htm

Brown, B., Eaton, S. E., Dressler, R., \& Jacobsen, M. (2015). Professional collaboration as responsive pedagogy. In P. Preciado Babb, M. Takeuchi, \& J. Lock (Eds.),Proceedings of IDEAS 2015: Designing Responsive Pedagogy Conference (pp. 101-108). Calgary, AB: Werklund School of Education, University of Calgary. Retrieved from https://prism. ucalgary.ca/handle/1880/50864

Council of Ministers of Education Canada (CMEC). (2007). Ministerial statement on quality assurance of degree education in Canada. Retrieved from http://www.cicic.ca/ docs/cmec/QA-Statement-2007.en.pdf

Dyjur, P., \& Lock, J. (2016). Three strategies for moving curriculum mapping online. Educational Developments, 17(2), 15-19.

Hendricks, C. (2016). Improving schools through Action Research: A reflective practice approach (4th ed.). Upper Saddle River, NJ: Pearson Education.

Kemmis, S., McTaggart, R., \& Nixon, R. (2014). The action research planner: Doing critical participatory action research. Singapore: Springer.

MacDonald, C. (2012). Understanding participatory action research: A qualitative research methodology option. Canadian Journal of Action Research, 13(2), 34-50.

McNay, M. (2009). Western guide to curriculum review - The University of Western Ontario-Teaching Support Centre. Retrieved from https://www.uwo.ca/tsc/resources/ pdf/PG_4_Curriculum.pdf

McNiff, J. (2013). Action research: Principles and practice. New York, NY: Routledge.

McNiff, J. (2014). Writing and doing action research. Thousand Oaks, CA: Sage Publications.

Miles, M., Huberman, A., \& Saldaña, J. (2014). Qualitative data analysis: A methods sourcebook. Thousand Oaks, CA: Sage Publications. 
Oliver, S. L., \& Hyun, E. (2011). Comprehensive curriculum reform in higher education: Collaborative engagement of faculty and administrators. Journal of Case Studies in Education, 2, 1-20. Retrieved from http://files.eric.ed.gov/fulltext/EJ1057195.pdf

Oliver, B., Ferns, S., Whelan, B., \& Lilly, L. (2010). Mapping the curriculum for quality enhancement: Refining a tool and processes for the purpose of curriculum renewal. Proceedings of the Australian Quality Forum: Quality in Uncertain Times (pp. 80-88). Gold Coast, Queensland, Australia: Australian Universities Quality Agency.

Parsons, J., Hewson, K., Adrian, L., \& Day, N. (2013). Engaging in action research: A practical guide to teacher-conducted research for educators and school leaders. Edmonton, AB: Brush Education.

Shulman, L. (2005). Signature pedagogies in the professions. Daedalus, 134(3), 52-59.

Shulman, L. (2007). Practical wisdom in the service of professional practice. Educational Researcher, 36(9), 560-563.

Spencer, D., Riddle, M., \& Knewstubb, B. (2012). Curriculum mapping to embed graduate capabilities. Higher Education Research and Development, 31(2), 217-231. http://dx.doi.org/10.1080/07294360.2011.554387

Uchiyama, K.P., \& Radin, J. L. (2009). Curriculum mapping in higher education: A vehicle for collaboration. Innovative Higher Education, 33(4), 271-280. doi: 10.1007/ s10755-008-9078-8

University of Calgary. (2015a). Academic quality assurance handbook: Curriculum reviews. Office of the Provost and Vice President Academic. Retrieved from http://www. ucalgary.ca/provost/activities/reviews

University of Calgary. (2015b). Werklund School of Education Graduate Programs in Education: Course-based programs curriculum review report, executive summary. Retrieved from https://www.ucalgary.ca/provost/files/provost/werklund_gpe_ curriculum_review_executive_summary_sept_25_2015.pdf

Willis, J., Inman, D., \& Valente, R. (2010). Completing a professional practice dissertation: A guide for doctoral students and faculty. Charlotte, NC: Information Age Publishing.

Wooltorton, S., Wilkinson, A., Horwitz, P., Bahn, S., Redmond, J., \& Dooley, J. (2015). Sustainability and action research in universities. International Journal of Sustainability in Higher Education, 16(4), 424-439. http://dx.doi.org/10.1108/IJSHE-09-2013-0111.

\section{Contact Information}

Michele Jacobsen

Werklund School of Education, University of Calgary

dmjacobs@ucalgary.ca

Michele Jacobsen is a professor and associate dean, Graduate Programs in Education, in the Werklund School of Education, University of Calgary. Dr. Jacobsen's design-based, case study, and action research focuses on K-12 and post-secondary learning, teaching, 
and leading in participatory, knowledge-building learning experiences that sponsor intellectual engagement. She studies online and blended learning environments, graduate education, academic publishing, teacher professional learning, and ethics in online research. She is the 2014 recipient of the Excellence in Leadership Award, and the 2001 and 2012 recipient of the Excellence in Teaching Awards, Werklund School of Education.

Sarah Elaine Eaton is an assistant professor in educational leadership in the Werklund School of Education, University of Calgary. Dr. Eaton's research is strongly interdisciplinary and includes scholarly investigations, action research, program and practice evaluation, and qualitative research on diverse topics relating to educational leadership in higher education, bilingual and second-language learning, building the capacity of online educators, and educational technology. Dr. Eaton was the 2015 recipient of the Excellence in Teaching Award, Werklund School of Education.

Barbara Brown, instructor and director of Professional Programs in Graduate Education, holds research and teaching expertise in educational leadership, educational technology, and teacher education. Dr. Brown is involved in various research projects: early learning and technology, high school redesign, focus on inquiry, STEM, K-9 learning, leaders professional learning, graduate education, and pedagogical leadership in high-needs schools. Dr. Brown was the recipient of the 2015 University of Calgary Teaching Award for Teaching in Online Environments, and the 2014 Excellence in Teaching Award, Werklund School of Education.

Marlon Simmons is an Associate Professor at the Werklund School of Education, University of Calgary. His scholarly work is grounded within sociology of education, Diaspora and culture, and governance of the self in educational settings. Related to Marlon's educational inquiry are the scholarship of teaching and learning and the role of sociomaterial relations with enhancing student learning.

Mairi McDermott is a post-doctoral scholar and sessional instructor in the Werklund School of Education, University of Calgary. Dr. McDermott's research is interdisciplinary while grounded in sociology of education with a post-structural feminist orientation to lit-eracy. She is interested in youth voice as a possibility for bridging the contemporary spaces between in school and out-of-school literacy practices of diverse urban youth. Her work concerns what voicings and identities are made possible through one's pedagogy, as peda-gogy comes to be informed through our personal and collective histories and experiences. 